\title{
POLINIZAÇÃo NATURAL, MANUAL E AUTOPOLINIZAÇÃO NO PEGAMENTO DE FRUTOS DE PINHEIRA (Annona squamosa L.) EM ALAGOAS ${ }^{1}$
}

\author{
ROUSSEAU DA SILVA CAMPOS ${ }^{2}$, EURICO EDUARDO PINTO DE LEMOS ${ }^{3}$, JAQUELINE FIGUEREDO DE OLIVEIRA ${ }^{4}$, \\ FERNANDA KARINA PEREIRA DA FONSECA ${ }^{4}$, ANTÔNIO DIAS SANTIAGO ${ }^{5}$, PERICLES GABRIEL BARROS ${ }^{2}$
}

\begin{abstract}
RESUMO - A pinheira (Annona squamosa L) é cultivada no Estado do Alagoas há mais de um século, sendo a principal cultura de valor econômico para centenas de pequenos agricultores. Um dos principais entraves para melhorar a produtividade da cultura é o baixo índice de polinização das flores e a conseqüente produção de frutos. Embora sejam morfologicamente perfeitas, as flores da pinheira apresentam dicogamia protogínica, fenômeno no qual a maturação dos carpelos acontece antes da maturação dos estames, inviabilizando a autofecundação. O presente trabalho objetivou estudar o efeito da polinização natural, manual e da autopolinização no número de frutos fixados em pinheiras. Foram utilizadas plantas de 4 anos de idade oriundas de pés-francos da variedade local "Crioula". As flores foram selecionadas na porção média das árvores em toda a sua circunferência. Foram utilizados os seguintes tratamentos: flores em polinização natural; flores cobertas para induzir a autopolinização; flores polinizadas com pincel usando pólen puro; flores polinizadas com pincel usando $75 \%$ de pólen e $25 \%$ de amido de milho; flores polinizadas com pincel usando $50 \%$ de pólen e 50 $\%$ de amido de milho; flores polinizadas com pincel usando $25 \%$ de pólen e $75 \%$ de amido de milho; flores polinizadas com bomba usando pólen puro; flores polinizadas com bomba usando $75 \%$ de pólen e $25 \%$ de amido de milho; flores polinizadas com bomba usando $50 \%$ de pólen e $50 \%$ de amido de milho; flores polinizadas com bomba usando $25 \%$ de pólen e $75 \%$ de amido de milho. Os resultados obtidos mostraram que o uso da polinização artificial com pincel ou com bomba polinizadora aumentou em até 10 vezes o número de frutos fixados em polinização natural ou em autopolinização. A adição do amido de milho seco como veículo para o pólen não reduziu a percentagem de frutos fixados e pode ser utilizado em até $50 \%$ da mistura sem reduzir a eficiência na polinização com pincel e em até $75 \%$ com bomba.
\end{abstract}

Termos para indexação: polinização artificial, pinha, fruta-de-conde

\section{NATURAL, ARTIFICIAL AND SELF POLLINATION ON FRUIT SET OF SUGAR APPLE (Annona squamosa L.) IN ALAGOAS}

\begin{abstract}
Sugar apple (Annona squamosa L) is a tropical fruit tree that has been cultivated in Alagoas for more than a century. It is one of the most important crop for hundreds of small farmers. One of the main constraints to improve this culture yield is its low pollination rate of their flowers. Although morphologicaly perfects, the flowers of sugar apple present the carpels maturation before pollen liberation in the anters preventing selfpollination. This work had the objective to study the effect of the natural, artificial and self-pollination on the number of fixed fruits in sugar apple. It was selected 40 four-year-old trees of local variety "Crioula" and flowers of the mean portion of the trees. They were applied the following treatments: natural pollination; self-pollination; hand pollination with $100 \%$ pollen using paintbrush; hand pollination with $75 \%$ of pollen and $25 \%$ starch using paintbrush; hand pollination with $50 \%$ of pollen and $50 \%$ starch using paintbrush; hand pollination with $25 \%$ of pollen and $50 \%$ starch using paintbrush; hand pollination with $100 \%$ of pollen using sprayer; hand pollination with $75 \%$ of pollen and $25 \%$ starch using sprayer; hand pollination with $50 \%$ of pollen and $50 \%$ starch using sprayer; hand pollination with $25 \%$ of pollen and $75 \%$ starch using sprayer. The results showed that the hand pollination with paintbrush or sprayer improved by ten fold the number of fixed fruits in natural pollination. The addition of starch to the pollen up to $50 \%$ of the mixture produced the same result of pure pollen.
\end{abstract}

Index Terms: custard apple, artificial pollination, annona.

\section{INTRODUÇÃO}

A pinheira (Annona squamosa L.) é cultivada no Estado do Alagoas há mais de um século. A sua produção localiza-se principalmente nos municípios de Palmeira dos Índios e Igaci, sendo a principal cultura de valor econômico para centenas de pequenos agricultores. Recentemente, a cultura se expandiu para outras áreas do Estado, sobretudo para a Zona da Mata, onde há maior disponibilidade de água para a irrigação dos pomares (Albuquerque, 1997).

Um dos principais entraves para melhorar a produtividade da cultura é o baixo índice de pegamento de flores e sua conseqüente transformação em frutos. Embora a pinheira produza uma grande quantidade de flores a cada safra, estima-se que somente cerca de 3 a 5 $\%$ de frutos efetivamente se formem. Além disso, os frutos são, na sua maioria, desclassificados pequenos e/ou malformados, possivelmente em decorrência do baixo número de carpelos polinizados (Fioravanço \& Paiva, 1994; Lemos et al., 1999).

Pereira et al. (2003), estudando a produção de pinheiras polinizadas artificialmente com pólen puro, em diversas horas do dia, encontraram diferenças significativas para o peso dos frutos, mas não no índice de pegamento dos mesmos. A época da polinização influiu significativamente na percentagem de frutos vingados de cherimóia, mostrando que a temperatura e a umidade relativa do ar, aliadas à polinização artificial, são fatores importantes no aumento da produtividade (Melo et al., 2002). Além disso, os autores observaram que, na polinização artificial, a percentagem de frutos perfeitos foi de quase quatro vezes superior à de frutos formados na polinização natural.

As flores da pinheira são originadas sempre em ramos novos, sendo pendentes, solitárias ou em grupo de duas a quatro. Embora sejam morfologicamente perfeitas, as flores da pinheira apresentam dicogamia protogínica, fenômeno no qual a maturação dos carpelos acontece antes da maturação dos estames, inviabilizando a autofecundação (Modesto \& Siqueira, 1981).

A maturação dos órgãos feminino e masculino, em momentos distintos, a morfologia floral com pétalas longas e base muito estreita, a lenta abertura das pétalas e a baixa freqüência de insetos polinizadores são fatores que dificultam a polinização das anonáceas (Torres et al.,1999; Calabrese et al.,1984).

Este trabalho objetivou determinar a influência da polinização natural, manual e autopolinização no pegamento das flores e a

\footnotetext{
(Trabalho 021/2004). Recebido: 11/03/2004. Aceito para publicação: 21/07/2004.

${ }^{2}$ Eng $^{\circ}$.Agr ${ }^{\circ}$.M.Sc., Secretaria de Agricultura do Estado de Alagoas,.Email: rousseau_campos@ hotmail.com.br,pgb@ @apeal.br

${ }^{3}$ Eng $^{\circ}$.Agr ${ }^{\circ}$.Prof. Adjunto, M.Sc., Ph.D., CECA, Universidade Federal de Alagoas, BR 104 Norte, Km 14, Tabuleiro, Maceió, AL, CEP 57072-970, Email: eepl@ceca.ufal.br,clcl@ufal.br

${ }^{4}$ Bolsistas PIBIC, CECA, UFAL., Email: jaquelinefigueredo@bol.com.br, fkpf@bol.com.br

${ }^{5}$ Eng $^{\circ}$.Agr ${ }^{\circ}$. M.Sc., Dr., CPATC-EMBRAPA, Email: santiago@cpatc.embrapa.br
} 
conseqüente formação de frutos em pinheiras cultivadas no Agreste do Estado de Alagoas.

\section{MATERIAL E MÉTODOS}

Este trabalho foi desenvolvido entre os meses de maio e julho de 2001, em pomar comercial da Fazenda São José, em Palmeira dos Índios, Alagoas (09²4’26”' Sul, 36³7’39”' Oeste), altitude de $342 \mathrm{~m}$, temperatura mínima de $18.8^{\circ} \mathrm{C}$, máxima de $27.7^{\circ} \mathrm{C}$ e média de $23.7^{\circ} \mathrm{C}$, umidade relativa de $81 \%$ e precipitação de $175 \mathrm{~mm}$. Foram utilizadas pinheiras de 4 anos de idade, oriundas de pés-francos da variedade local "Crioula". Escolheram-se 40 árvores em floração, divididas em 4 blocos (repetições), com 10 tratamentos e 1 árvore por parcela. As flores foram selecionadas na porção média das árvores em toda a sua circunferência. Foram escolhidas flores bem conformadas com cerca de $25 \mathrm{~mm}$ de comprimento que já haviam concluído o ciclo de crescimento, mas que não tinham iniciado a abertura. No total, 60 flores foram etiquetadas para cada tratamento sendo 15 flores por árvore.

Foram utilizados os seguintes tratamentos: 1) Flores em polinização natural; 2) Flores cobertas com saco de papel para induzir a autopolinização; 3) Flores polinizadas com pincel usando $100 \%$ de pólen; 4) Flores polinizadas com pincel usando $75 \%$ de pólen e $25 \%$ de amido de milho; 5) Flores polinizadas com pincel usando $50 \%$ de pólen e $50 \%$ de amido de milho; 6) Flores polinizadas com pincel usando $25 \%$ de pólen e $75 \%$ de amido de milho; 7) Flores polinizadas com bomba usando $100 \%$ de pólen puro; 8) Flores polinizadas com bomba usando $75 \%$ de pólen e $25 \%$ de amido de milho; 9) Flores polinizadas com bomba usando $50 \%$ de pólen e $50 \%$ de amido de milho; 10) Flores polinizadas com bomba usando $25 \%$ de pólen e $75 \%$ de amido de milho.

As flores selecionadas foram protegidas um dia antes da abertura com um saco de tecido para evitar a polinização natural, salvo no tratamento 1, onde o interesse era a polinização natural. Para os demais tratamentos, no momento da polinização, os sacos foram retirados, salvo no tratamento 2 , onde o objetivo era a autopolinização. A polinização foi feita com pincel de pêlo de camelo $\left(n^{\circ} 02\right)$ e bomba polinizadora entre 15 e 18 horas do dia da abertura das flores no estágio feminino.

Para a obtenção do pólen a ser usado no estudo, colheram-se flores no final do estádio feminino - entre 17 e 17h30 -, no dia anterior à polinização, as quais foram armazenadas por cerca de 24 horas em sacos de papel e deixadas à temperatura ambiente (média de $26^{\circ} \mathrm{C}$ ) até a liberação dos grãos de pólen (fase masculina). Após ser observada a liberação do pólen das anteras, levaram-se as flores a uma peneira para separar os grãos de pólen dos restos florais.

A aplicação do pólen puro ou em mistura foi feita sobre os carpelos das flores abertas quando se apresentavam com aspecto úmido e brilhante, indicando a sua receptividade. Nos tratamentos com pincel ou com bomba, foram feitas duas aplicações dirigidas aos carpelos da flor. Em seguida, as pétalas foram unidas com fita adesiva para se evitar a chegada de pólen de qualquer outra fonte. Após 15 dias da aplicação dos tratamentos, avaliaram-se o número de flores pegas e o início da formação dos frutos.

\section{RESULTADOS E DISCUSSÃO}

De maneira geral, os resultados obtidos 45 dias após a polinização das flores mostraram que o número de frutos formados aumentou em até dez vezes nos tratamentos onde se aplicou a polinização manual com pincel ou bomba em comparação com a polinização livre ou autopolinização forçada (Tabela 1). Melo et al. (2002), estudando a polinização manual da cherimóia, registraram aumentos de $312 \%$ no número de frutos vingados e de $389 \%$ no número de frutos perfeitos. Os autores comprovaram ainda que a autopolinização não promoveu a formação de frutos, confirmando os resultados deste trabalho. Já Arriaga et al. (1997) observaram um incremento de $75 \%$ no pegamento de flores e de $105 \%$ no tamanho de frutos quando utilizaram a polinização artificial da cherimóia.
TABELA 1 - Influência do método de polinização na formação de frutos de pinheira 45 dias após a polinização das flores.

\begin{tabular}{ccccc}
\hline $\begin{array}{c}\text { Método de } \\
\text { Polinização }\end{array}$ & $\begin{array}{c}\text { \% frutos } \\
\text { formados }\end{array}$ & $\begin{array}{c}\text { Diâmetro } \\
\text { frutos (cm) }\end{array}$ & $\begin{array}{c}\text { Comprimento } \\
\text { frutos (cm) }\end{array}$ & $\begin{array}{c}\text { \% frutos } \\
\text { perfeitos }\end{array}$ \\
\hline PN & $10 \mathrm{~d}$ & $2.3 \mathrm{~b}$ & $1.5 \mathrm{c}$ & $23 \mathrm{~d}$ \\
AP & $0 \mathrm{e}$ & $0 \mathrm{c}$ & $0 \mathrm{~d}$ & $0 \mathrm{e}$ \\
PAP 100\% & $95 \mathrm{a}$ & $3.6 \mathrm{a}$ & $3.8 \mathrm{a}$ & $96 \mathrm{a}$ \\
PAP 75\% & $97 \mathrm{a}$ & $3.1 \mathrm{ab}$ & $3.3 \mathrm{a}$ & $84 \mathrm{ab}$ \\
PAP 50\% & $98 \mathrm{a}$ & $3.3 \mathrm{ab}$ & $3.3 \mathrm{a}$ & $83 \mathrm{ab}$ \\
PAP 25\% & $82 \mathrm{~b}$ & $2.9 \mathrm{ab}$ & $2.9 \mathrm{ab}$ & $74 \mathrm{~b}$ \\
PAB 100\% & $92 \mathrm{a}$ & $3.5 \mathrm{a}$ & $3.1 \mathrm{ab}$ & $92 \mathrm{a}$ \\
PAB 75\% & $90 \mathrm{a}$ & $3.9 \mathrm{a}$ & $4.0 \mathrm{a}$ & $88 \mathrm{ab}$ \\
PAB 50\% & $88 \mathrm{~b}$ & $2.6 \mathrm{~b}$ & $2.5 \mathrm{~b}$ & $82 \mathrm{ab}$ \\
PAB 25\% & $63 \mathrm{c}$ & $3.2 \mathrm{ab}$ & $3.1 \mathrm{ab}$ & $60 \mathrm{c}$ \\
\hline CV (\%) & 9,607 & 16,51 & 13,44 & 12,546 \\
\hline
\end{tabular}

${ }^{1}$ Média de 4 repetições por tratamento e 15 flores por parcela. Total de 60 flores por tratamento. Médias seguidas de mesma letra não diferem estatisticamente entre si, a 5\% de probabilidade, pelo teste de Tukey. $\mathrm{PN}=$ polinização natural; $\mathrm{AP}=$ autopolinização; $\mathrm{PAP}=$ polinização artificial com pincel $; \mathrm{PAB}=$ polinização artificial com bomba.

A polinização manual feita com pincel não proporcionou variações significativas na taxa de formação de frutos entre as concentrações mais altas de pólen utilizadas, exceto para a concentração de $25 \%$, que foi significativamente menor (82\%). Por outro lado, a eficiência da polinização artificial com bomba medida pela percentagem de frutos fixados caiu significativamente nos níveis de $50 \%$ e $25 \%$ (Tabela 1). Taxas de formação de frutos em pinheira, superiores a $80 \%$, foram também obtidas por Pereira et al. (2003), quando utilizaram pólen puro aplicado com pincel.

Os resultados obtidos neste trabalho com a polinização natural livre foram relativamente baixos (10\%), confirmando os resultados em anonáceas obtidos por Gazit et al. (1982), Fioravanço \& Paiva (1994) e Melo et al. (2002). Nas condições da Índia, Kumar et al. (1977) observaram que a fixação de frutos em pinheiras, com polinização natural por insetos, oscilou entre $8,6 \%$ e $9,6 \%$. Valores variáveis de $50 \%$ a $90 \%$ de aumento no pegamento dos frutos foram relatados para a pinheira e gravioleira quando se utilizou a polinização manual em comparação com a polinização livre (São José et al., 1999).

No trabalho aqui apresentado, todas as flores protegidas e forçadas à autopolinização não formaram frutos, confirmando a autoincompatibilidade de flores isoladas por não haver coincidência nos estágios de maturação do pólen e receptividade dos estigmas (dicogamia protogínica). Estudos com Annona cherimola mostraram também que a autopolinização das flores não conduziu à formação de frutos (Melo et al., 2002).

A mistura do pólen com o amido de milho não interferiu na formação dos frutos até a percentagem de $50 \%$ quando se aplicou o pólen com pincel ou 75\% quando se aplicou o pólen com a bomba, mostrando que é possível fazer-se uma economia de pólen de 25 a 50\% sem perder a eficiência no pegamento das flores de pinheira. Todavia, a percentagem de frutos perfeitos foi reduzida significativamente a partir da inclusão de $75 \%$ de amido de milho na mistura com pincel ou bomba (Tabela 1).

Geralmente, considera-se adequada uma proporção de 1 flor colhida para cada 3 flores a serem polinizadas. Neste trabalho, a mistura dos grãos de pólen ao amido de milho mostrou que a mesma mantém a viabilidade dos grãos e facilita o seu manuseio por lhe aumentar o volume e a sua visibilidade nos carpelos após a sua aplicação.

As diferenças observadas entre os dois métodos de polinização manual (pincel e bomba), principalmente nas concentrações mais baixas de pólen, indicam que o método de polinização artificial com pincel foi mais eficiente e permite uma economia de $50 \%$ de pólen. Tal economia se traduz pela necessidade de menor número de flores a serem coletadas na véspera da polinização para o mesmo número de flores polinizadas. $\mathrm{Na}$ prática, necessita-se do pólen de 1 flor para cada 4,5 flores a serem 
polinizadas com pincel ou o pólen de 1 flor para cada 3,75 flores a serem polinizadas com bomba, ou seja, uma economia de $25 \%$ de flores. A aplicação mais localizada do pólen com o pincel parece explicar os melhores resultados deste em relação à bomba.

Todos os frutos formados foram acompanhados nos primeiros estádios de crescimento, e a percentagem de frutos perfeitos foi superior a $80 \%$, observada aos 45 dias após a polinização, nos tratamentos com até $50 \%$ de amido de milho, diminuindo significativamente nos tratamentos com $75 \%$ de amido de milho ou polinização natural (Tabela 1).

\section{CONCLUSÕES}

Os resultados obtidos neste estudo permitem concluir que o uso da polinização artificial, com pincel ou com bomba polinizadora, aumenta em até 10 vezes o número de frutos formados e em até 4 vezes o número de frutos perfeitos quando comparada à polinização natural livre feita por insetos. A adição do amido de milho seco como veículo para o pólen não reduz a percentagem no número frutos formados em até $50 \%$ da mistura, mas reduz o número de frutos perfeitos a partir de $75 \%$ sem reduzir a eficiência na polinização com pincel e em até $75 \%$ com bomba.

\section{REFERÊNCIAS BIBLIOGRÁFICAS}

ALBUQUERQUE, H.C. Situação atuação atual e perspectivas para as anonáceas no Estado de Alagoas. In: SÃO JOSÉ, A. R.; SOUZA, I.V.B.; MORAIS, O. M.; REBOUÇAS, T.N.H. (Eds.)Anonáceas, produção e mercado: pinha, graviola, atemóia e cherimólia. Vitória da Conquista: Universidade Estadual do Sudoeste da Bahia. 1997. p.150-152.

ARRIAGA, M.R.; GARZA, A.M.; LOPEZ, L.L. Cherymoya hand pollination and its relation with harvest and fruit characteristics. In: CONGRESO INTERNACIONAL DE ANONACEAS, 1., 1997,
Chapingo. Memórias... p. 19-27.

Calabrese, F.; Michele, A.; Raimond, A.; Panno, M. Aspetti e problemi della coltivazione dell Anona (Annona cherimola L.). Rivista di Fruticoltura, Ravenna, n.8.p.4-47,1984.

Fioravanço, J.C.; Paiva, M.C. Tratos culturais. In: Fioravanço, J.C.; Paiva, M.C. (Eds.) Fruticultura, cultivo das anonáceas: ata, cherimóia e graviola. Porto Alegre: EVANGRAF, 1994. Cap. 8, p.62-77.

Gazit, S.; GAlon, I.; PODOLER, H. The role os Nitidulid Beetles in Natural Pollination of Annona in Israel. Journal of the American Society for Horticultural Science, Alexandria, v. 107, n. 5, p. 849-852, 1982.

Kumar, R.; Honda, M.N.; Singh, D.K. Studies on the floral biology of Custard apple (Annona squamosa Linn.). Indian Journal of Horticulture, Bangolore, v.34, n.3, p.252-256, 1977.

Lemos, E.E.P.; Pereira, P.C.C.; CAVAlCANTE, R.L.R. Artificial Pollination of Soursop (Annona muricata L.), to Improve Fruit Yield and Quality. In: Torres, J.T.S, Hermoso Gonsales, J.M \& Farre Massip, J.M. (Eds.). In: CONGRESSO INTERNACIONAL DE ANONÁCEAS, 2. 1999, Anais... Universidade de Chiapas, 1999, p.247-250.

MELO, M.R.; POMMER, C.V.; KAVATI, R.; TOKUNAGA, T. Polinização naturale artificial da cherimóia (Annona cherimola Mill.) no Estado de São Paulo. Revista Brasileira de Fruticultura, Jaboticabal, v.24, n.3, p.631-633, 2002.

PEREIRA, M.C.T.; NIETSCHE, S.; SANTOS, F.S.; XAVIER, A.A.; CUNHA, L.M.V., NUNES, C.F., SNATOS, F.A. Efeito de horário de polinização artificial no pegamento e qualidade de frutos de pinha (Annona squamosa L.). Revista Brasileira de Fruticultura, Jaboticabal, v.25, n.2, p.203-205, 2003.

SÃO JOSÉ, A.R.; REBOUÇAS, T.N.H.; SILVA, A.C.; NIETO-ANGEL, D.; BONFIM, M.P. El cultivo de guanábana (Annona muricata L.) y saramuyo (A squamosa L.) en Brasil. In: CONGRESSO INTERNACIONAL DE ANONÁCEAS, 2., 1999, Anais... Universidade de Chiapas, 1999, p.224-229.

Modesto, Z.M.M.; SiqueIRA, N.J.B. Botânica. São Paulo: EPU, 1981. 167p. 